This PDF is a selection from an out-of-print volume from the National Bureau of Economic Research

Volume Title: The Youth Labor Market Problem: Its Nature, Causes, and Consequences

Volume Author/Editor: Richard B. Freeman and David A. Wise, eds.

Volume Publisher: University of Chicago Press

Volume ISBN: 0-226-26161-1

Volume URL: http://www.nber.org/books/free82-1

Publication Date: 1982

Chapter Title: The Youth Labor Market Problem: Its Nature Causes and Consequences

Chapter Author: Richard B. Freeman, David A. Wise

Chapter URL: http://www.nber.org/chapters/c7869

Chapter pages in book: (p. 1 - 16) 


\title{
1 \\ The Youth Labor Market Problem: Its Nature, Causes, and Consequences
}

\author{
Richard B. Freeman and David A. Wise
}

Youths and young adults have traditionally worked less than older persons. While some youths work less than adults because they are devoting a major portion of their time to schooling or to leisure activities, others work less because they have great difficulty obtaining jobs or because they are in the midst of switching their primary activity from schooling to employment, a process that involves considerable searching and job changing before settling into more or less permanent employment.

In recent years, as large numbers of youths have entered the job market, and because some groups of young persons have lower employment rates than comparable groups in the past, there has been rising concern about the operation of the youth labor market. Youth unemployment has become a major issue, as evidenced by congressional legislation such as the Youth Employment and Demonstration Projects Act of 1977.

Under the auspices of the National Bureau of Economic Research (NBER), economists from several universities have been engaged in extensive investigation of the nature of youth employment, the causes of changes in youth employment rates over time, the causes of individual differences in employment experiences, and the consequences of youth unemployment. This chapter represents a distillation of the findings of that work. We will summarize briefly the principal results of the NBER analysis and then describe the nature of these results in greater detail.

\subsection{Dimensions of the Youth Employment Problem}

1. One of the most important lessons of our analysis is that standard published statistics may not adequately measure the dimensions of youth

Richard B. Freeman is professor of economics at Harvard University and director of the NBER's program in labor studies. David A. Wise is Stanbough Professor of Political Economy at the John F. Kennedy School of Government and an NBER research associate. 
employment and joblessness. First, different sources of employment information lead to widely differing estimates of the number of employed youths. The Current Population Survey (CPS), which provides the official government statistics, reports a smaller number of youths employed than do other government-financed surveys.

Second, the traditional distinction between being unemployed (out of work and looking for a job) and being out of the labor force (out of work and not looking for a job) appears less clear for young persons than for older workers. Many youths are on the borderline between seeking work and not seeking work, and switch frequently from one group to the other. Some youths who are out of the labor force may in fact desire to work but have simply given up looking. On the other hand, some youths who are classified as unemployed may not be seeking work as actively as unemployed adults. In addition, many youths who are classified as unemployed are also in school full time, an activity that many would consider as productive as work. While for all age groups the difference between unemployment and being out of the labor force is ambiguous, the ambiguity is especially great for youths.

2. Constant references to the youth employment problem, as if all or the majority of young persons had difficulty obtaining jobs, appear to misinterpret the nature of the difficulty. Youth joblessness is in fact concentrated, by and large, among a small group who lack work for extended periods of time. Over half of the male teenage unemployment is, for example, among those who are out of work for over six months, a group constituting less than $10 \%$ of the youth labor force and only $7 \%$ of the youth population. The concentration of joblessness among a small group means that lack of employment is a major problem for that group, but also that most youths have little difficulty obtaining work.

3 . The youths who make up the relatively small group that is chronically without work have distinct characteristics. They are disproportionately black; disproportionately high school dropouts, and disproportionately residents of poverty areas. Over time, the percentage of black youths with jobs has fallen while the proportion of white youths with jobs has not, implying a deterioration in the employment chances of black youths. Despite the extremely high rate of unemployment among black youths, though, the fact is that since there are many more whites than blacks in the population, most unemployment in even this chronic group is accounted for by whites.

While the employment rate of black youths has fallen sharply over the past decade, the wages of young blacks have risen relative to those of white youths. By the mid-1970s the wage rates of black and white youths with comparable levels of education were approximately equal. 


\subsection{The Causes of Youth Employment Problems}

4. One of the most important determinants of youth employment is the strength of the economy as a whole. When the aggregate level of economic activity and the level of adult employment is high, youth employment is also high. Quantitatively, the employment of youths appears to be one of the most highly sensitive variables in the labor market, rising substantially during boom periods and falling substantially during less active periods.

Another frequently mentioned determinant of youth employment is the proportion of youths in the population. According to our analysis, however, while the increase in the relative number of young people in recent years has adversely affected youth employment, its primary impact has been to depress youth wages relative to adult wages.

A third important determinant of youth employment is the minimum wage; our evidence confirms previous findings that by making youth labor more expensive, increases in the minimum wage reduce youth employment.

5. At any given time, youths with certain background characteristics tend to have lower employment rates than youths with other characteristics. Some of the characteristics associated with lower employment appear to be unrelated to wages. Youths from poor families frequently tend to be employed less often than youngsters from wealthier families, although once employed both groups earn about the same wages. As noted earlier, blacks are employed less often than whites, but earn about the same wages when employed. The sizable increase in black youth wage rates may have contributed to the relative deterioration in employment of black youths.

6. Some forms of preparation during high school are related to subsequent labor market experiences of youths while others are not. Vocational training in high school shows little, if any, relationship to labor market success, even among youths who obtain no further education after high school. Academic performance in high school, on the other hand, is positively related to both employment and wages after graduation and entry into the labor force. And most important and possibly surprising, youths who work in high school work much longer per year when they enter the labor force full time than teenagers who do not work while in high school, and they earn more per hour as well.

\subsection{The Consequences of Youth Employment and Unemployment}

7. Much of the recent discussion about youth unemployment is focused on the fear that lack of work during one's youth will contribute substantially to unemployment later in life. This fear appears to be 
greatly exaggerated. We have found that unemployment immediately following the completion of school has virtually no effect on employment three or four years later. Indeed, initial wage rates have almost no effect on later wage rates. However, early unemployment has a sizable negative effect on later wage rates.

8. While the precise links have yet to be established, the changing employment situation of young black persons has been associated with other widespread social developments: increases in youth crime, drug use, violence in schools, and youth suicide, suggesting that the consequences and correlates of the problem go beyond standard economic issues. The finding that youth unemployment is concentrated among a small group of youths in itself suggests that this group may also have other social problems.

In short, this NBER volume has found that many commonly held views about the youth employment problems are erroneous and that many critical aspects of the problems have been inadequately understood: youth unemployment, rather than being widespread among a large proportion of youths, is in fact concentrated among a small group; the nature of youth employment and unemployment differs substantially from that of adult employment and unemployment; and youth unemployment generally does not have the major long-term consequences on later employment that some have feared, though it does affect later wages.

\subsection{The Nature of the Youth Employment Problem}

A few basic statistics will motivate and provide background for our subsequent discussion. Employment and unemployment rates for selected years by race, sex, and age are shown in table 1.1 (Freeman and Medoff, chapter 3).

These data show divergent levels and trends in the percentages of youths with jobs and the percentage unemployed; they describe the primary characteristics of the youth labor market.

Although youth unemployment is sometimes perceived and portrayed as a crisis of youth in general, these data do not support this interpretation. The employment rate of white male youths has changed only modestly in the past two decades; indeed, the trend has been upward since the mid-1960s. The percentage of white females employed has also risen substantially, even in the 1970s.

On the other hand, since 1954 the percentage of black youths with jobs has fallen dramatically and there has been a correspondingly large increase in the black unemployment rate. This disturbing trend is even more troublesome in light of the fact that it is a relatively recent one. In 1954 , approximately equal percentages of black and white youths were employed. Since that time, unemployment rates for black youths have 
Employment and Unemployment Rates 1954-77

\begin{tabular}{|c|c|c|c|c|c|c|c|c|}
\hline & \multicolumn{4}{|c|}{ White } & \multicolumn{4}{|c|}{ Black and other } \\
\hline & 1954 & 1964 & 1969 & 1977 & 1954 & 1964 & 1969 & 1977 \\
\hline \multicolumn{9}{|l|}{ Men } \\
\hline \multicolumn{9}{|c|}{ Percentage Employed } \\
\hline Age: $16-17$ & 40.6 & 36.5 & 42.7 & 44.3 & 40.4 & 27.6 & 28.4 & 18.9 \\
\hline $18-19$ & 61.3 & 57.7 & 61.8 & 65.2 & 66.5 & 51.8 & 51.1 & 36.9 \\
\hline $20-24$ & 77.9 & 79.3 & 78.8 & 80.5 & 75.9 & 78.1 & 77.3 & 61.2 \\
\hline $25-54$ & 93.8 & 94.4 & 95.1 & 91.3 & 86.4 & 87.8 & 89.7 & 81.7 \\
\hline \multicolumn{9}{|c|}{$\begin{array}{l}\text { Percentage of Labor } \\
\text { Force Unemployed }\end{array}$} \\
\hline Age: $16-17$ & 14.0 & 16.1 & 12.5 & 17.6 & 13.4 & 25.9 & 24.7 & 38.7 \\
\hline $18-19$ & 13.0 & 13.4 & 7.9 & 13.0 & 14.7 & 23.1 & 19.0 & 36.1 \\
\hline $20-24$ & 9.8 & 7.4 & 4.6 & 9.3 & 16.9 & 12.6 & 8.4 & 21.7 \\
\hline $25-54$ & 3.9 & 2.8 & 1.5 & 3.9 & 9.5 & 6.6 & 2.8 & 7.8 \\
\hline \multicolumn{9}{|c|}{ Women } \\
\hline \multicolumn{9}{|c|}{ Percentage Employed } \\
\hline Age: $16-17$ & 25.8 & 25.3 & 30.3 & 37.5 & 19.8 & 12.5 & 16.9 & 12.5 \\
\hline $18-19$ & 47.2 & 43.0 & 49.2 & 54.3 & 29.9 & 32.9 & 33.9 & 28.0 \\
\hline $20-24$ & 41.6 & 45.3 & 53.3 & 61.4 & 43.1 & 43.7 & 51.5 & 45.4 \\
\hline $25-54$ & 40.1 & 41.0 & 46.2 & 54.1 & 49.0 & 52.7 & 56.3 & 57.4 \\
\hline \multicolumn{9}{|c|}{ Percentage of Labor } \\
\hline Age: $16-17$ & 12.0 & 17.1 & 13.8 & 18.2 & 19.1 & 36.5 & 31.2 & 44.7 \\
\hline $18-19$ & 9.4 & 13.2 & 10.0 & 14.2 & 21.6 & 29.2 & 25.7 & 37.4 \\
\hline $20-24$ & 6.4 & 7.1 & 5.5 & 9.3 & 13.2 & 18.3 & 12.0 & 23.6 \\
\hline $25-54$ & 5.0 & 4.3 & 3.2 & 5.8 & 8.3 & 8.4 & 5.0 & 9.8 \\
\hline
\end{tabular}

risen and their employment position has deteriorated greatly. As can be seen in the figures of table 1.1, the unemployed proportion of black youths has increased relative to black adults as well as relative to white youths. (In 1954, the unemployment rate of black youths was about 1.5 times the rate for black adults; by 1977, the youth rate was almost 4 times the adult rate.)

Thus, to the extent that trends in the data signify a deterioration in the employment of youths, that deterioration is concentrated among black youngsters. Nonetheless, because a much greater proportion of the population is white, the vast majority of unemployed youths are white.

What the numbers in the table above do not reveal is that almost half of the teenagers classified as unemployed are also in school. The unemployment of a young person in school, most would agree, represents less loss to society than that of an adult seeking full-time work.

The Bureau of Labor Statistics defines unemployment as the ratio of persons looking for work to the number employed plus the number looking. According to this (BLS) definition, $18 \%$ of male teenagers aged 16 to 19 were unemployed in October 1976 . Since most full-time students 
are not included in the youth labor force, however, this figure overstates the fraction of young persons who are ready to work but have no productive way to spend their time. Just $4.9 \%$ of teenagers are both unemployed and not in school. On the other hand, the unemployment data ignore youths who are not in the labor force. In October 1976, 9\% of male teenagers 16 to 19 years old were either unemployed or out of the labor force and not in school. Moreover, only $70 \%$ of the out-of-school teenagers (many of whom were high school dropouts) held jobs according to the Current Population Survey data. ${ }^{1}$

Whichever groups are considered, unemployment is concentrated among those with the lowest levels of education. Among out-of-school teenagers, for example, persons with less than 12 years of school account for $58 \%$ of the unemployed. Unemployment rates are much higher among high school dropouts than among high school graduates. Moreover, unemployment is also concentrated among relatively few persons: those unemployed for very long periods. If we add up all periods of unemployment for male teenagers, for example, we find that $54 \%$ of the total is composed of persons who are unemployed for more than six months of the year. Even more striking, $10 \%$ of all teenagers account for more than half of total teenage unemployment (Feldstein and Ellwood, chapter 2; Clark and Summers, chapter 7). The majority of young persons move in and out of the labor force and obtain jobs with ease; many youths either experience no unemployment at all between transitions or are unemployed only for very short spells. However, the concentration of unemployment among a small fraction of youths has presumably higher social costs than if unemployment were evenly distributed among all youths.

In short, the data suggest that most teenagers do not have substantial employment difficulties, but that for a minority of youths, there are long periods without work that constitute severe problems. This group is composed in large part of high school dropouts and contains black youths in numbers disproportionate to their representation in the population.

It is commonly believed that young persons have much more difficulty in finding jobs than their adult counterparts. Measured by the lengths of spells of unemployment, the evidence does not support this view. The average duration of periods of unemployment for teenagers is about the same as the average for adults. ${ }^{2}$ However, many spells of teenage unemployment end not when a job is found, but when the young person drops out of the labor force. Teenagers average as much as five months between loss of a job and attainment of a new job (Clark and Summers, chapter 7). (The volatility of the youth labor force, with persons frequently entering and leaving the officially measured labor force, raises questions about the adequacy of the data in distinguishing between the two states.)

Unemployment rates can be broken down into two components: the rate at which persons change jobs or switch from out of the labor force 
into the labor force, multiplied by the rate at which the changers or switchers are unemployed. Analysis of these two components of unemployment shows that young persons are unemployed more than adults because they change jobs or situations more often than adults, not because they have a greater chance of unemployment given a change in status.

About one-fourth of young men aged 18 to 24 change jobs in a year, compared to less than one-tenth of men aged 35 to 54 . The differential proportion of job changers by age is itself largely attributable, according to Mincer and Leighton's calculations, to differences in seniority by age. Low-seniority workers, of necessity primarily young workers, change jobs frequently, while high-seniority workers, of necessity primarily older workers, change less frequently and are as a result less likely to be unemployed. One of the key factors behind the high rate of youth joblessness is the high mobility and short job tenure of the young (Mincer and Leighton, chapter 8).

Finally, we emphasize that the interpretation of all these data is complicated by uncertainty about the accuracy of their magnitudes. Recent large-scale surveys that interview young persons themselves rather than resident adults in a household as is common in the widely used Current Population Survey, reveal higher rates of employment and different rates of unemployment than do the official government statistics.

For example, for October 1972, employment rates for out-of-school male high school graduates, based on the National Center for Educational Statistics study of the high school class of 1972 , were $88 \%$ for whites and $78 \%$ for blacks (Meyer and Wise, chapter 9 ). The comparable Current Population Survey data, the basis for official Bureau of Labor statistics numbers, implied substantially lower unemployment rates of $82 \%$ and $68 \%$ respectively. Similar differences arise in comparing the Current Population Survey rates with those based on the National Longitudinal Survey of Young Men. A large portion of the difference among the various rates can be attributed to who answers the survey questions in each case. Youths report more employment activity for themselves than is reported by the household member most likely to respond to government population surveys, a youth's mother. The differences in reports are larger for in-school youths with full-time jobs (Freeman and Medoff, chapter 4). It is important to remember that until the discrepancy in survey results is completely resolved and the "correct" rate of youth employment determined, there will be ambiguity about the causes and consequences of the problem.

\subsection{The Consequences: Market Determinants of Youth Employment}

Whether a youth is employed or not depends partly on the strength of the economy and on broad demographic conditions, and partly on indi- 
vidual characteristics of the youth himself. The aggregate determinants are those that influence the average level of youth employment at a given time; the individual influences are those that determine differences among individuals at a given time. We shall discuss the broader influences on the average youth employment rate in this section, and individual differences in the next section.

The most important aggregate determinant is the level of economic activity. There is strong evidence that when the economy is strong, youths as well as adult workers are better off. A widely used indicator of the level of aggregate economic activity is the unemployment rate for adult males. Young persons living in areas where the local unemployment rate is high have more spells of unemployment than comparable youths in areas with strong economies (Mincer and Leighton, chapter 8).

Analysis of differences among metropolitan areas, based on 1970 Census data, indicates that an increase in the adult male unemployment rate is associated with disproportionately large decreases in the proportion of youths who are employed. When the adult unemployment rate rises by one percentage point, the proportion of youths who are employed drops by the following percentage amounts (Freeman, chapter 5):

All Young Men
Aged: $\begin{array}{rl}16 \text { to } 17 & 5 \% \\ 18 \text { to } 19 & 2 \% \\ 20 \text { to } 24 & 3 \%\end{array}$

\begin{tabular}{|c|c|}
\hline Dut-of-school Yol & $\mathrm{gg} \mathrm{Mer}$ \\
\hline Aged: 16 to 17 & $5 \%$ \\
\hline 18 to 19 & $3 \%$ \\
\hline 20 to 24 & $3 \%$ \\
\hline
\end{tabular}

Evidence based on changes in adult unemployment over time confirms these findings. The time series data show that a one percentage point increase in the adult male unemployment rate is associated with a $5 \%$ decrease in the proportion of young men aged 16 to 19 who are employed. ${ }^{3}$ Thus youth employment is highly sensitive to cyclical movements in the economy.

A second indicator of aggregate economic activity, the growth rate of personal income, also shows a substantial positive relationship to youth employment, according to our comparative analysis of metropolitan areas. If these indicators reflect aggregate demand, then demand forces have a substantial effect on youth employment.

Two other measures of aggregate economic conditions are also strongly related to youth employment. One is the "industrial mix" in the area where the young person lives, and the other is the average income level in the area. Based on comparisons across metropolitan areas, youth employment is higher in those areas with a large number of industries that traditionally employ many young workers. Some of these industries have large numbers of jobs that do not require extensive training; other industries may simply have developed production processes, and orga- 
nized their work forces, in such a way that large numbers of young persons are accommodated. The "industrial mix" has an approximately equal effect on the employment of teenagers aged 16 to 19 as the effect of aggregate economic activity (as measured by the adult unemployment rate), but has smaller effects on those aged 20 to 24 (Freeman, chapter 5).

In addition, the extent of poverty in an area affects the employment chances of youths. Those areas with greater proportions of families living in poverty, and those youths living in officially designated poverty areas, tend to have lower rates of youth employment (Rees and Gray, chapter 13; Freeman, chapter 5). This is true even among areas with similar levels of adult unemployment, personal income growth rates, and industrial mix. Thus some characteristics of youths, or of the demand for young workers in poor areas, are not captured by these other geographic characteristics.

Another frequently mentioned aggregate determinant of the percentage of youths who are employed is the proportion of the total population who are young. Over the past decade and a half, this proportion has increased dramatically. It is argued that production technologies and institutional arrangements may make the economy slow to adapt to large changes in the relative numbers of younger versus older workers, thereby increasing unemployment and reducing the number of youths who work.

Our evidence suggests that while there may be some such effects, especially for 16 to 17 year olds, the large increase in the number of the youths relative to adults in the labor force has affected wage rates more than employment. The fact that during the period of rapid increase in the youth proportion of the population the fraction of youths employed did not fall casts doubt on the importance of the number of young persons as a major determinant of their employment.

The large increases in the youth labor force in the summer months without a corresponding increase in youth unemployment also bring into question the effect of the proportion of youths in the population on their employment rate. During the summer months, the labor market absorbs large numbers of teenagers. Although teenage labor force participation has been almost $40 \%$ higher in July than the annual average, in July the teenage unemployment rate has been somewhat lower than the annual average (Clark and Summers, chapter 7).

Evidence from geographic areas with different proportions of young persons, however, suggests that a one-percentage-point increase in the proportion of the population that is young may lead to a noticeable reduction in the employment rate of 16 to 17 year olds, but not those aged 18 to 19 , or those aged 20 to 24 . Additional evidence based on movements over time in the employment of youths suggests that increases in the relative number of youths are, in general, associated with declines in the 
employment ratio of most youth groups (Wachter and Kim, chapter 6), though not by enough to dominate the other factors contributing to youth employment.

Perhaps the greatest effect of the increasing proportions of youths in the population has been a decrease in youth wages relative to adult wages, rather than a decrease in youth employment. The earnings of black and white male youths, as a percentage of earnings of adult males, are shown in the tabulation below for 1967 and 1977 and for selected age groups (Wachter and Kim, chapter 6).

\begin{tabular}{cccccc} 
& \multicolumn{2}{c}{ White } & & \multicolumn{2}{c}{ Black and Other } \\
Age & 1967 & 1977 & & 1967 & 1977 \\
\cline { 2 - 3 } 18 & 54 & 49 & & 44 & 44 \\
20 & 66 & 58 & & 63 & 52 \\
22 & 79 & 63 & 59 & 54 \\
24 & 87 & 75 & 60 & 63
\end{tabular}

The earnings of young white men in all age groups declined rather dramatically relative to adult wages between 1967 and 1977 . On the other hand, the earnings of black youths have not changed much, on average, relative to adult earnings. Thus the market adjustment to larger numbers of youths has been reflected to some extent in a relative decline in youth wages. Indeed, for white youths, wages may have been the primary equilibrating mechanism, allowing the employment rate to be maintained in the face of large increases in the relative number of youths in the population. Traditional supply-and-demand analysis suggests that whenever the supply of any group of workers increases relative to the demand for them, the larger numbers will be employed only at a lower wage rate. In contrast to the decline in the white youth wage rates relative to adult wages, the wages of black youths-both male and female-rose relative to the wages of white youths. At the same time, black youths were finding it increasingly difficult to find jobs. It is likely that the change in the relative wages of the two groups contributed to the deterioration in black versus white employment.

There is also a wide body of evidence showing that the employment of both white and black youths is handicapped by the minimum wage, presumably because the minimum wage is higher than employers are willing to pay some youths. Since the number of young persons looking for jobs can change when the minimum wage changes, the minimum wage has a more systematic effect on employment than on unemployment of the young. Some results suggest larger effects on employment for 16 to 17 year olds, and for black youths in general, than for other groups (Wachter and Kim, chapter 6). Both the evidence on the relationship between youth employment and youth wage rates and the evidence on 
the effect of the minimum wage are consistent with evidence from the United Kingdom, where youth employment appears to be quite sensitive to the level of youth wages (Layard, chapter 15). The downward trend in youth wages relative to adult wages in the U.S. may, however, have been a more important determinant of youth employment in the 1970s than changes in the legal minimum. In addition, although most discussions of the minimum wage focus on its likely effects on youth employment and wages, it is also possible, in theory, for the minimum wage to shorten the duration of teenage jobs and thus increase the frequency with which youths change jobs (Hall, chapter 14).

Though some headway has been made in determining the causes of changes in youth employment experiences, it is important to stress that major questions remain unanswered, in particular the differential pattern of change between white and black youths.

\subsection{The Causes: Individual Determinants and Correlates of Youth Employment and Wages}

We now turn to individual characteristics that contribute to differences in employment experience among youths. These are attributes that influence the experience of one youngster relative to another at a given time. It is important to realize from the start that most of the variation in employment and wages among individuals cannot be explained by differences among them that we can observe and measure, such as education or family income. Most of the variation is due to factors, such as individual tastes, opportunities, or chance, that we are unable to explain. Nonetheless, the effect of some characteristics is very substantial. The most important determinants of youth employment and wages follow.

\subsubsection{Education}

As we have already emphasized, high school dropouts are employed fewer weeks per year on average than high school graduates. More generally, out-of-school youths of any age with education below the average for their age group are employed noticeably less than other out-of-school youths in that age group (Rees and Gray, chapter 13).

Particular educational experiences-may also affect employment and wages. Much public discussion and policy have centered on the potential influence of job training on later ability to find and do jobs. Yet we have found that vocational training in high school is virtually unrelated to subsequent employment and wage rates, even for persons who obtain no further education after leaving high school. Academic performance, on the other hand, seems to be positively related both to the number of weeks per year that youths are employed and to their wage rates after entering the labor force full time (Meyer and Wise, chapter 9). 
In addition, there is a very strong relationship between hours worked while in high school and later employment and wage rates, with persons who work during high school employed many more weeks per year and having higher wage rates when they enter the labor force full time than those who do not work in high school (ibid.). We have not as yet differentiated adequately between two possible explanations for these relationships: that working in high school reflects an underlying commitment and ability to perform well in the market, that the work experience itself enhances these characteristics, or most likely, that both of these situations interact. The relationship suggests, however, that high school work experience may hold significant potential for enhancement of later work experience and at the same time raises the possibility that unemployment among in-school youths, while different from that of out-ofschool youths, may result in lost preparation for future work.

\subsubsection{Family Background}

It is widely accepted that early family experiences are likely to affect later employment as well as the educational attainment of youths. We have no knowledge of the early family experiences of youths, but we do have access to measures of some family characteristics such as income. We have found that such measures are related to both school and labor force experiences, but the relationships are not entirely what we expected. For all youths, family background, as measured by parents' income, shows little relationship to employment. Thus family income apparently has little to do with the inclination of youths to seek employment or with their ability to find jobs, although it may affect inclination and ability to find work in an offsetting way. However, youths whose brothers and sisters have jobs are more likely to have jobs themselves (Rees and Gray, chapter 13). This finding is subject to several interpretations. It may reflect local labor market conditions or characteristics common to all family members, or it could mean that employed siblings help other youths in the family to secure jobs.

Though children from wealthier families seem to be no more successful in finding jobs than those from poorer families, we have found that youngsters from wealthier families obtain jobs that pay more per hour (Meyer and Wise, chapter 9). The reasons for this pattern have yet to be determined.

We have also found that youths in female-headed households and in households on welfare tend to have fewer jobs than youths from other families, though the differences are not sizable. Again, while this result is not surprising, it is not clear why this relationship occurs. Youths in families where the adult heads are less likely to have jobs may themselves be less likely to seek employment. On the other hand, youngsters from such families may simply have fewer job opportunities. Here too, how- 
ever, once a youth is employed, family characteristics are not related to wage rates. It is possible, of course, that those who are the most productive on the job are also the most likely to seek employment and the most likely to be hired.

\subsubsection{Race}

As noted earlier, black youths have noticeably lower chances of working than white youths, although the magnitude of black/white differences in employment differ by survey; in some surveys the differences are modest for high school graduates. In contrast, black and white youth wages tend to be quite similar for all educational levels, so that employed young blacks earn about as much as employed young whites. One reason for the downward trend in black youth employment has been a marked increase in the school attendance of young blacks. The increase in black schooling, however, explains only a small proportion of the black/white differences in employment that have arisen since 1954.

We find it implausible to explain the decreased employment in terms of discrimination of the traditional type, particularly in view of increased legal and other pressures placed on discriminators. Perhaps other factors having to do with the social conditions in inner city slums have worsened and have contributed to the weakened employment situation of blacks. No empirically verified explanation presently exists.

\subsection{The Consequences}

Many persons have expressed the fear that periods of unemployment early in one's working career could have substantial adverse effects on employment in future years. We have found that these fears are largely unfounded, and that the evidence has often been misinterpreted to imply that there are large effects. In fact, there is little evidence that time spent out of work early in a youngster's career leads to recurring unemployment (Meyer and Wise, chapter 9; Ellwood, chapter 10). Rather, the cost of not working is the reduction in wages persons suffer later because they failed to accumulate work experience, something employers reward. That early unemployment has little effect on later unemployment does not mean that young men and women who have unusually low levels of employment early in their working lives are unlikely to work less in later years. Young men who do not enroll in college and spend some time unemployed their first year out of school, for example, are twice as likely to experience unemployment again than are their peers who escaped early unemployment (Ellwood, chapter 10). But this effect is due almost entirely to persistence of individual differences such as education, academic ability, and motivation. The existence of such characteristics creates a positive correlation between time worked in one year and that 
worked in the next and subsequent years. To isolate the effect of unemployment itself on future unemployment, it is necessary to control for these individual differences. Once individual differences are controlled for, so that persons can be compared only on the basis of early work experience, there is little relationship between employment experience after high school and employment four years later.

This conclusion holds for widely differing groups of young men and probably for young women as well. It is supported by evidence on young men who do not enroll in college, including high school dropouts, who were followed in the National Longitudinal Survey of Young Men (ibid.). It is also supported by evidence on a large national sample of high school graduates surveyed as part of the National Longitudinal Study of the High School Class of 1972 (Meyer and Wise, chapter 9). Comparable evidence based on young women in the National Longitudinal Survey of Young Women supports this conclusion as well (Corcoran, chapter 11). This does not mean, of course, that we should be unconcerned that some persons will always tend to have poorer labor force experience than others. But it does mean that initial employment in itself does not increase or decrease employment over the long run. Thus, for example, simply creating jobs for persons right after high school should not be expected to increase the number of weeks that they will be employed four years later.

Since wage rates increase with experience, there is, however, a cost to not working today. Individuals who are unemployed in their youth obtain lower wages in subsequent years because they have accrued fewer years of experience. The effect for high school graduates three or four years later appears to be modest, and it is somewhat less for women than for men (Meyer and Wise, chapter 9; Corcoran, chapter 11). Evidence for young men with less than fourteen years' education showed considerably higher estimates of the effects of early experience on wage rates three or four years later, upwards of $15 \%$ per year out of work (Ellwood, chapter 10). All of this evidence is consistent with previous research findings on the relationship between earnings and experience. In short, unemployment does not by itself foster later unemployment, but the effect of unemployment is felt in lower future wages, and this effect may be quite substantial.

Not only is there little effect of early employment on subsequent employment, but initial wage rates in themselves have little effect on subsequent wage rates. Once persistent individual differences are controlled for, there is virtually no relationship between wage rates early in a person's labor force experience and wages earned several years later (Meyer and Wise, chapter 9). After allowing for individual characteristics, a low paying job one year will not by itself lead to a low paying job 
three or four years later, according to our findings. Thus the fear that a low-level job one year-as indicated by a low wage rate-will harm one's chances of obtaining a better job in later years appears to be unfounded.

These findings are distinct from the observation that unemployment varies according to occupational characteristics. Young persons working in occupations with high initial wages but slow wage growth, and in occupations whose work force is highly mobile across industries also have higher rates of unemployment (Brown, chapter 12).

\subsection{Conclusions}

The NBER research has illuminated several aspects of youth employment and unemployment. We have found that severe employment problems are concentrated among a small proportion of youths with distinctive characteristics but that for the vast majority of youths lack of employment is not a severe problem. Thus the youth unemployment crisis should be thought of as one specific to only a small proportion of youths, not as a general problem. Black youths are less likely to be employed than white youths, but once employed the two groups have similar wage rates; this rough equality is a recent development. While work experience and academic performance in school have been found to be related to employment and wages, vocational training in school has not. Aggregate economic activity has been found to be a major determinant of the level of youth employment.

Early employment experience has virtually no effect on later employment after controlling for persistent characteristics of individuals, such as education. Similarly, wages earned upon entry into the labor force have no effect themselves on wage rates earned a few years later. But not working in earlier years has a negative effect on subsequent wages because wage increases are related to experience.

Finally, we have found large differences between employment and unemployment rates based on Current Population Survey data-the traditional source for such information-and evidence based on two other recent large-scale surveys. This uncertainty not only leads to questions about the basic magnitude of youth employment and unemployment but complicates analysis of youth employment experiences as well.

\section{Notes}

1. Feldstein and Ellwood (chapter 2); based on data from October, 1976 (Current Population Survey). Wachter and Kim (chapter 6) give comparable figures using annual averages, including summer months, for 1978 . 
2. Mincer and Leighton (chapter 8) find duration to be longer for adults than young persons in their analysis.

3. Clark and Summers (chapter 7). A comparable estimate for nonwhites in this age group is over $6 \%$. Estimates obtained from a separate time series analysis are also consistent with this general order of magnitude (Wachter and Kim, chapter 6). 